\title{
Perspectives for Geosciences in the 21st Century
}

Geology will play an increasingly important role in the understanding of the Earth in the new century. Geologists the world over are fully aware of their responsibilities in the challenges of environment and development and are better prepared to contribute to mankind for a sustainable society. These are reflected to a certain extent in this collection.

This article incorporates 18 abstracts originally included in the Abstract Volume of the 31st International Geological Congress held in Brazil, 2000, focusing mainly on environmental geosciences and mineral resources. The abstracts are re-published here by courtesy of the 31st IGC Scientific Committee.

\section{Geosciences for development in Africa in the new millennium}

D. Muhongo, Geological Society of Africa. E-mail: muhongo@udsm.ac.tz

The projected population of the African continent in 2000 will be about 820 million and its average annual growth rate of the total population in this new millennium will be the highest (ca 2.5\%) when compared to other continents. In the Africa's decade of renaissance (1990-2000), its average positive economic growth rate was about $2-5 \%$, but about $40 \%$ of its population in the Sub-Saharan Africa falls into the absolute poverty category,

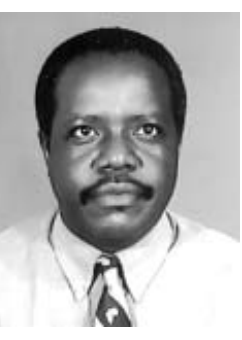
according to UN records. By 1995, the Africa's external debt burden amounted to about US \$330 billion for which Sub-Saharan Africa accounted for about US $\$ 231$ billion.

Africa has enormous earth resources. It has the world's largest reserves of strategic minerals such as $\mathrm{Cr}(82 \%)$, Co (54\%), Mn (52\%), Au (30\%), U (29\%), V (20\%) and many undiscovered and underestimated earth resources. Development and sustainable management of these resources are necessary for poverty eradication in Africa. Hence, geosciences have a key role to play so as to increase the economic growth rate averaging 5-7\% a year which is deemed necessary for poverty alleviation and eradication in Africa. Thus, geosciences in Africa and elsewhere have to provide solutions to societal or community problems. They have to contribute significantly to the socio-economic development of the peoples of the African continent. For Africa, geoscientific objectives in this new millennium should be focused on:

1. provision of sufficient earth resources (e.g. water, energy, minerals),

2. provision and maintenance of quality education and research in geosciences,

3. sound environmental management, timely assessment of natural hazards and mitigation of disasters; and

4. advising and influencing politicians and decision makers on matters pertaining to the development and management of Africa's earth resources for sustainable socio-economic development of the continent.

\section{Geosciences for Europe's environment in the 21st century}

Ed. F.J. de Mulder and Richard N. Annells.

E-mail: demulder@wxs.nl

While the 20th century was the era in which mankind learned to travel in the air and outer space, the 21 st century will witness dramatic progress in the discovery and utilisation of the subsurface. The national governments of the European Union are developing a shared administration based in Brussels and individual regions will play a more important role in its affairs, particularly in cross-border environmental legislation issues. Since 1984 European geoscientists have developed continental co-operation

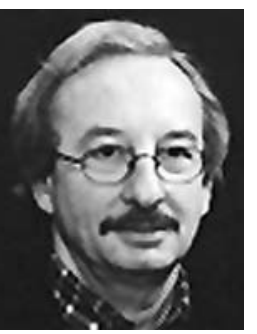
enabled by successive four-year EU R\&D Framework Programmes. In 1995, the Geological Surveys of the 15 EU member countries plus Norway formed the association EuroGeoSurveys to increase their input to EU policy making through a permanent Bureau in Brussels.

In the 21st century Europe geoscientists will initially focus on making integrated databases of subsurface information available across the Web. By 2025 the subsurface conditions of large regions will become 3D visualized and coupled with prediction models. By 2050 Europe will be entirely mapped geologically at the 1:50,000 scale. By 2075 the influence of subsurface behaviour on socio-economic conditions at any spot in Europe will be visible to clients on line. Geoscientific expertise will further focus on smart, sustainable use of the subsurface by applying advanced geo-knowledge for efficient utilisation of the Earth's physical and (bio)chemical potentials. New exploration and exploitation techniques will target deeper levels for new materials and safe waste disposal sites. Geoscientists will become key members of new clusters focused on societal problems in a dramatically changed society.

\section{Environmental geoscience in the 21st century in Scandinavia}

O. Selinus - Geological Survey of Sweden, P.O. Box 670, SE-75128 Uppsala, Sweden. E-mail: olle.selinus@sgu.se

Environmental geoscience has a long history in the Scandinavian countries. Already in the early 1970s geological surveys in these countries commenced environmental geochemical mapping on a regular scale. At the same time the topic of Geomedicine was developed and especially in Norway this science started early. Some future developments can be seen in the 21st century:

- Environmental geochemistry will be continuously developed, for example, biogeochemistry indicating bioavailable elements in the environment.

- Medical Geology will be continuously developed in cooperation with medics and veterinarians.

- Urban geoscience is gaining an increasing importance in Scandinavia.

- Waste deposits are of increasing concern. Geoscientists will be important in monitoring these and in remediation activities.

- Environmental geology in general concerning groundwater resources and risk areas of different kinds will be further developed.

- An increasing importance of using geoscientists in monitoring and remediation activities in, e.g., the Eastern world and other regions where environmental activities so far have been neglected. 


\section{Trends in environmental geosciences: Observations from North America}

Roy J. Shlemon - P.O. Box 3066, Newport Beach, California 926590620, USA. E-mail: rshlemon@jps.net

The last decade of budget cuts in Canada and the United States reduced environmental geoscience research in academia and government agencies. However, recent improvements in the general economy have ameliorated this problem. The U.S. Geological Survey, for example, has had much of its budget (and personnel) restored, although priorities now emphasize applied research. Groundwater remediation continues relatively unabated.

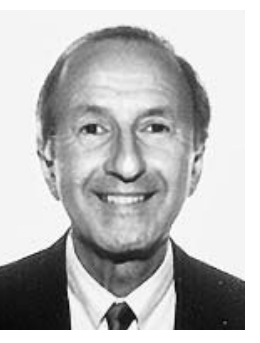
And many consulting environmental geoscientists are in demand as expert witnesses in litigation.

Much environmental geoscience research is driven by regulation, particularly for wetland delineation, contaminant mitigation, and seismic and floodplain zoning. Many jurisdictions also require full disclosure of potential active faults, slope stability problems, contaminants and other geologic hazards before a property can be sold.

The near future will likely see little dramatic change in techniques and level of environmental geoscience research. Remediation methods will undoubtedly improve; but changes in public policy are more likely to influence the direction of geoscience research. For example, earthquake damage may best be mitigated by engineering design, rather than by substantial increase in fault mapping and characterization. And floodplain and coastal zone construction may be restricted or reduced by eliminating government-subsidized insurance that tends to encourage rebuilding and hence repeated damage in such hazard areas.

\section{Geosciences and environmental land-use decision-making process in developing countries: Perspectives towards the 21st century in Colombia and Latin America}

Elkin Velasquez - Geoenvironmental Engineering Department, INGEOMINAS, Diagonal 53 No. 34-53, Santafè de Bogotá, Colombia.E-mail: elvelasquez@yahoo.com

At the end of this century, Colombia is involved in an important land-use and environmental planning process. The New Political Constitution (1991) and several environmental laws propose the basis for this and the Central Government is preparing the Structural LandUse Planning Law. Moreover, the agenda for peace negotiation between parts in conflict includes the items of land-use planning and natural resource management as very important

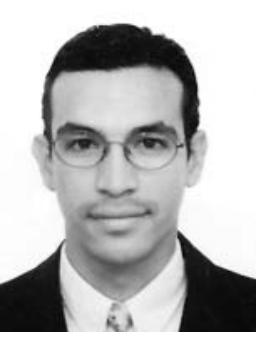
topics. In that sense, geosciences, and specifically environmental geology, have to adapt its classical techniques and tools for resolving specific social and economical needs implicit in those processes.

From that, geopotential analysis is proposed as a tool to improve environmental valuation and communication of geoscientific knowledge. Social and economical criteria obtained from analysis of stakeholders expectations are used to get four dimensions on environmental valuation: development value, strategic value, patrimonial value and sensibility value. Geopotential indicators are relevant to determining those values. GIS permits to optimize the management of geopotential indicators and information.

Geopotential assessment leads to taking into account geoscientific information in prospective evaluation. Spatial scenario analysis, following different prospective techniques, may be obtained based on geopotential and land carrying capacity maps.

Different phases of this new methodology, which has shown their pertinence in environmental decisions in Colombia, are presented here as well as some perspectives for systematic production of geopotential maps at a regional scale.

The application of that tools is analyzed for other countries of Latin America.

\section{Environmental geoscience in Southeast Asia: current trends and future challenges}

J.J. Pereira, Institute for Environment and Development (LESTARI), Universiti Kebangsaan Malaysia, Bangi, Malaysia. E-mail: jjpereira@hotmail.com

Southeast Asia is a high growth area, both from the population and development perspectives. As a result of rapid development, the region has been subjected to tremendous land use changes, hastening certain geological processes, which threaten human safety and the environment. In addition, human activity depending on limited resources such as land, soil, water and minerals has also adversely impacted the ecology of the region. The impor-

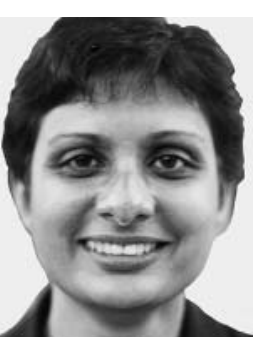
tance of environmental geoscience was brought to fore in Southeast Asia over the past two decades due to geological hazards. Problems associated with slope stability, subsidence, erosion and floods are among the geological hazards common to all countries of this region, particularly in densely populated areas where natural conditions are made worse by human intervention. Other issues that presently require environmental geoscience inputs include resource and energy utilization, conservation of physical heritage, waste disposal as well as identification and cleanup of polluted land and water. Solutions to these problems require multidisciplinary inputs as well as new knowledge and approaches. Pilot initiatives that relate to integrated management of basins, watersheds and coastal zones, which involve scenario generation, are being undertaken in Malaysia, Thailand and Indonesia. These initiatives, based on remote sensing, have brought in a wealth of information to the region. However, on its own, such data cannot provide conclusive answers to ensure the integrity of the environment. There is an urgent need to fill knowledge and data gaps for improved management and decision-making in this region and environmental geoscience has an important contribution to make, in this context.

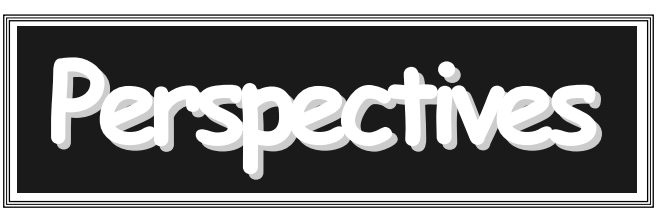




\section{Permafrost in the 21st century}

Jerry Brown - International Permafrost Association, Woods Hole, MA 02543, USA. E-mail: jerrybrown@igc.apc.org

Twenty-five percent of the land mass of the Northern Hemisphere, the Antarctic continent and some mountainous regions of South America are underlain by permafrost conditions or earth materials that remain below freezing for more than several years. Permafrost is currently warming in many regions of the Earth. Temperature variations in permafrost are indicative of changes in surface boundary conditions, in part the result of

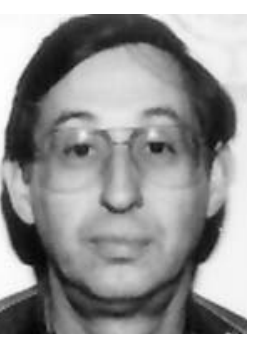
changes in climate and differences in surface and subsurface conditions, including snow cover, vegetation, geomorphology, geology, and ground-ice content. Models of permafrost distribution under different 21 st century climate scenarios predict decreases in the areal extent of near-surface permafrost. The initial results are distabilization and erosion of the thawing, ice-rich ground, and increased slope instability in the mountains. Permafrost degradation has important implications for engineered structures and landscape processes including those related to hydrology, vegetation, and sources and sinks of greenhouse gases. In order to evaluate the magnitude of the changes in the permafrost temperature of the Earth, an international global monitoring system (Global Terrestrial Network-Permafrost; GTN-P) is under development. This information is required for the improvement of predictive models and impact assessments including those of the Intergovernmental Panel on Climate Change (IPCC), and to further our understanding of the responses of permafrost conditions and processes to climate variability and change.

\section{Electromagnetics in earthquake prediction}

Seiya Uyeda, Toshiyasu Nagao, Katsumi Hattori, Tohru Yamaguchi and Yoshiaki Orihara, Riken - International Frontier Research Group on Earthquakes at Earthquake Prediction Research Center, Tokai University, Shimizu, Japan. E-mail: suyeda@ riken.gp.jp

Despite general pessimistic views on earthquake prediction, in particular on shortterm prediction, researches based on electromagnetic methods have recently been extremely active, revealing promising results in many parts of the world such as Greece, China, Italy, Russia, Ukraine, France, USA, Mexico, Japan to name a few. In some cases, actual short-term prediction has been in practice. Major recent developments in this new

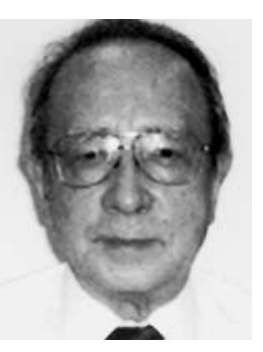
science are reviewed critically, but constructively, because their recognition in wider scientific community seems to be unduly lagging far behind the real progress of investigation. Important characteristics of probable electromagnetic precursors are their appearances in a wide frequency band, covering from DC to VHF ranges, possibly involving many different processes. Reported precursory phenomena can be classified into two categories: one is the pre-seismic emission of signals from focal zone and the other is the anomalous transmission of electromagnetic waves over focal regions. The methods of measurement and the physical mechanisms for their generation, transmission and reception can be diverse and close international and interdisciplinary cooperation would be vital for comprehensive understanding of the whole process that may be called 'Lithosphere-Atmosphere-Ionosphere Interaction'. Interdisciplinary cooperation would be particularly useful as the researchers on this subject are specialists of widely different fields, including geoelectromagnetism, solid state physics, radio sciences and engineering, informatics, seismology and of course geology.

\section{Global trends in earthquake disasters}

A. Allmann and A. Smolka, Geoscience Research Group, Munich Reinsurance Company. E-mail: AAllmann@MunichRe.com

The four earthquake disasters in 1999 in Colombia, Turkey, Greece and Taiwan have demonstrated in a nutshell the deficiencies in earthquake preparedness encountered in countries at various stages of economic development. Whereas none of the lessons taught by these earthquakes was new, each of the events had its own specifics which highlighted a particular issue relating to earthquake preparedness or to seismological aspects. Particularly intriguing

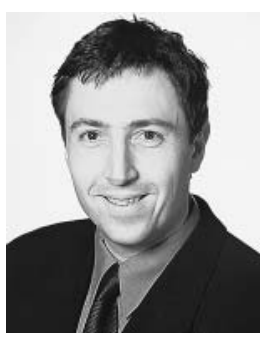
were the losses to the Hsinchu Industial Park in Taiwan caused by lack of anchoring of highly sensitive equipment and by lack of redundancy in the power supply, thus demonstrating in exemplary fashion the vulnerability of a highly technologized, modern society. A common factor in all these events was the inadequate implementation of seismic building regulations. Furthermore, these disasters lent proof to the observation that the pure growth of urban regions on the one hand and the introduction of highly sensitive technologies on the other have created risks which did not exist before. This results in a global trend towards dramatically increasing earthquake losses, which is further analyzed on the basis of statistics on economical and insured earthquake losses for the time period since 1950.

\section{Catastrophic events: A hands-on pre- college earth science curriculum for the 21st century}

C. O'Donnell, Macgregor, I., and Wright, T. - Smithsonian Institution, Washington, DC, USA; E-mail: codonnel@nas.edu Woodwell, G. - Mary Washington College, Fredericksburg, VA, USA.

For years, educators have stressed that students learn better by doing-especially in the sciences. The National Science Resources Center-an organization jointly sponsored by the Smithsonian Institution and United States National Academy of Sciences-strongly believes that students of all ages learn more science content and skills when they engage in collaborative investigation and discovery using everyday materials and the basic equipment of science.

For the first time the United States National Science Education Standards have identified the Earth Sciences as one of the core sciences in the K-12 curriculum. These requirements charge us with the need to develop new teaching materials, and train a new cohort of teachers capable of teaching Geoscience in the 21st century.

Natural hazards-including earthquakes, volcanic eruptions, tornadoes, and hurricanes-are exciting topics for students. Catastrophic Events, developed by the National Science Resources Center, is a hands-on Earth Science module designed to give students the opportunity to model and investigate firsthand the phenomena that cause and result from catastrophic events.

In addition to understanding the scientific processes that cause natural hazards, students address these events from a personal and social perspective. Using modern technologies that transcend time and space, students witness currently active catastrophic events around the world. They examine how these events occur, how they impact our lives, and how we have learned to reduce the risks associated with them. This course has considerable potential to be used in many different countries where natural hazards pose serious threats to life and property. 


\section{Perspectives for mineral exploration in the 21 st century}

Brian J. Skinner - Yale University, Department of Geology and Geophysics, New Haven, Connecticut 06520-8109, USA.

E-mail: brian.skinner@yale.edu

Demand for minerals and the need for increased deposit-discovery rates will continue to grow in the century ahead. The factors driving the growth will be a doubling of the global population, increasing rates of per capita consumptions, continuing technological innovations, and the penetration of technology into all parts of all societies.

All metallic mineral resources to date have come from the continental crust. The recent discovery of mineralization in the oceanic crust suggests that ocean mining may commence in the 21 st century. Nevertheless, the frequency of mineralization in the oceanic crust appears to be so much less than that in the continental crust that exploration and mineral production in the 21 st century will continue to be primarily focused on the continental crust.

So far only half of the continental crust has been explored for mineralization. The rest is covered by unmineralized sediments that are too thick for current geophysical or geochemical exploration methods to penetrate. Although many mineral deposits probably remain to be found in the currently prospectable half of the crust, the challenge for the 21 st century is to carry out exploration under ever deeper cover, and to eventually be able to prospect the entire continental crust.

The last 50 years has been a time when a lot of elegant research into ore deposit genesis, rock-water interactions, stable isotope geochemistry, and tectonic settings, has been carried out, but that research has not yet played a significant role in mineral exploration. However, this body of research, combined with an ever-growing database of deposit models, will become a critical component of exploration in the 21 st century.

\section{Marine minerals at the new millennium}

Peter A. Rona - Institute of Marine and Coastal Sciences and Department of Geological Sciences, Rutgers University, 71 Dudley Road, New Brunswick, N.J. 08901-8521, USA (rona@imcs.rutgers.edu)

A new view of marine minerals is emerging that links inorganic with organic processes and raises environmental issues. On the continental shelf recovery of common materials comprising sand and gravel for construction and seawater for desalinization will grow. Mineral sands containing $\mathrm{Au}, \mathrm{Pt}$, gemstones, Sn- and Ti-minerals will be targeted and traced seaward. Diamonds have developed into a mining industry offshore Namibia and South

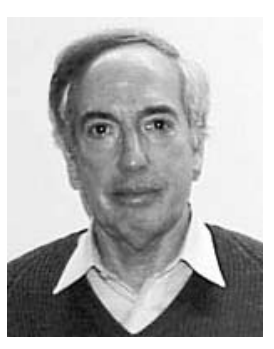
Africa with annual output near US\$1 billion. Deep seabed deposits comprising manganese nodules $(\mathrm{Mn}, \mathrm{Cu}, \mathrm{Ni}, \mathrm{Co}$; water depths 4000-6000 m), cobalt-rich ferromanganese crusts (Fe, Mn, Co, Ni, $\mathrm{Pt}$; water depths 500-2500 m), and massive sulfide deposits $(\mathrm{Cu}, \mathrm{Fe}$, $\mathrm{Zn}, \mathrm{Ag}$, Au; water depths $1000-4000 \mathrm{~m}$ ) will be mined. The cobaltrich ferromaganese crusts accumulate on rocky seabed elevations of seamounts, islands, and oceanic plateaus where they are difficult to harvest. Massive sulfides are deposited from seafloor hot springs which are sources both of the metals and of chemical energy utilized by heat-tolerant bacteria to manufacture their food at the base of a vent ecosystem linking inorganic with organic processes. The bacteria are sources of organic compounds for use in industrial processes and pharmaceuticals and may themselves relate to the base of the evolutionary tree of life. Mining of the metallic minerals and the bioproducts produced at seafloor hot springs has the potential to benefit society and to threaten the environment. A theme of the 21 st century will be reconciling the conflict between societal benefits and environmental impacts of marine mining.

\section{Critical review of world uranium deposits and resources for the $21 \mathrm{st}$ century}

Douglas Underhill and Mohamad Tauchid (retired) - International Atomic Energy Agency, Vienna, Austria.

E-mail: d.underhill@iaea.org

In 1999 mine production was about $50 \%$ of the 61,500 tonnes uranium (tU) used by the nuclear industry to generate $16 \%$ of the world electricity supply. A recent WEC-IIASA study defines a wide range of possible future nuclear electricity generation. Annual uranium requirements in 2050 range from $52,000 \mathrm{tU}$ in the low case, to $283,000 \mathrm{tU}$ in the high case. Cumulative requirements to 2050 for the low, mid and high cases are, respectively $3.39,5.35$ and 7.58 million $\mathrm{tU}$. A new IAEA analysis of uranium supply gives a compilation of non-production supplies, known uranium resources and estimated undiscovered resources sufficient to supply reactors to 2050. To 2020, production from mines will be supplemented by existing inventories, blended down warhead material, and other sources. Known resources occur in 125 uranium deposits. For the mid case, about $75 \%$ of demand to 2020 , and $90 \%$ to 2050 , would be met from mine production. An increased proportion of mine output is required for the high case. Important deposit types that could fuel nuclear power in the 21 st century, under conditions of mid to high growth, are those with large resources producible at low to medium cost. The production costs of the various deposits range from $<\$ 13.00 / / b \mathrm{U}_{3} \mathrm{O}_{8}$ (low) to $>\$ 50 / \mathrm{lb} \mathrm{U}_{3} \mathrm{O}_{8}$ (very high). Base load production is from the giant, high-grade unconformity-type deposits in Canada, very large-, medium-grade Australian unconformity-type deposits, and the giant $\mathrm{Cu}-\mathrm{U}-\mathrm{Au}$ breccia complex Olympic Dam deposit. Sandstone-type deposits amenable to ISL recovery are important, but are limited by their small average size. Known, high or very high cost resources will be required to meet demand, unless exploration discovers new low cost deposits. Because of the long lead times for discovery, environmental assessment and project development, exploration will need to be started soon if the discoveries are to have an impact on uranium supply prior to 2050. Otherwise uranium by-product from phosphate production and recovery from seawater could also provide large supplies at medium and very high cost, respectively. 


\section{Where will the world's future mineral resources come from?}

Klaus J. Schulz - U.S. Geological Survey, 954 National Center, Reston, VA, USA 22092, kschulz@usgs.gov, and the Global Mineral-Resource Assessment Team.

Global demand for mineral resources will continue to increase for the foreseeable future because of the continuing increase in global population, and the desire and efforts to improve living standards worldwide. The ability to meet this growing demand for minerals is affected by concerns about possible environmental degradation caused by mineral production and by competing land uses. Informed planning and decisions concerning sustainabil-

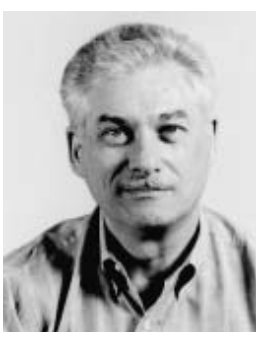
ity and resource development require a long-term perspective and an integrated approach to land-use, resource, and environmental management worldwide. These, in turn, require unbiased information about the global distribution of identified and especially undiscovered mineral resources, the economic factors influencing their development, and the environmental consequences of their exploitation. In response to the growing concern about the sustainability of nonfuel mineral production and environmental quality, the U.S. Geological Survey has initiated a project to evaluate the feasibility of conducting assessments of the world's undiscovered mineral resources. The project is gathering information regarding the current status and availability of global minerals-related information, and the distribution of ecosystems and their response to minerals development. The project also is experimenting with prototype global assessments for selected metallic and non-metallic deposit types to help improve assessment methodology and define protocols needed to conduct global-scale assessments. The project seeks cooperation and collaboration with other organizations and industry involved in international mineral-resource and related environmental issues.

\section{The Earth in the 21st century: geological object or subject}

Othon H. Leonardos - Centre f. Sustainable Development - UnB, Brasilia, Brazil. E-mail: othonhl@bol.com.br

Care for the Environment with responsibility towards the poor is already a major consensus shared by 180 nations. As soil, river and ocean life systems become more and more exploited with the misuse of science and technology and our own habitat vanishes, Society will demand a major rupture with the past and build up an ethics-based modernity for sustainable development. In such a scenario, science and geological knowledge, in particular, will be precious tools for the purpose of serving Life and Earth - not just for serving the technology of power owners and to satisfy market demands. Earth scientists may then exercise their overall social and environmental responsibility towards the sustainability and the quality of life for the future generations. Environmental geoscience is a pleonasm that reflects the fragmentated way geology has gone as it broke apart from all Life sciences and disregarded the overall human dimension. Geology is an environmental science and geologists must know why, for whom and for what purpose are they working. They must also be aware of the consequences of their work before becoming blindly specialised. They must retain transdisciplinary wisdom as they become involved in geologic analysis. It is time geologists join the overall effort of building up a science for the
Earth and understand our subject-object relationships with Mother Earth.

\section{Petroleum geochemistry: applications to reservoir management and exploration in the 21st century}

Kenneth E. Peters - ExxonMobil Upstream Research Company, Houston, Texas U.S.A. 77252.

E-mail: ken_peters@email.mobil.com

Petroleum geochemistry is an established science that reduces the risk associated with exploration and production of crude oil and natural gas. Since its early development, petroleum geochemistry is periodically declared to be mature. This is misleading because among geologists and industry management, the term mature is associated with extensively explored basins with little further potential. Petroleum geochemistry is mature in that powerful tools were developed to characterize source rocks and petroleum and these have been remarkably successful. It is estimated that about two-thirds of the worldwide petroleum resource has been discovered and geochemistry continues to play a critical role. However, petroleum geochemistry is not a mature predictive science. Many enigmas remain whose solutions could yield tremendous competitive advantages in exploration and production.

Landmarks in petroleum geochemistry include: the petroleum system concept, reliable correlation based on chemometrics of biomarker and isotopic data, recognition that certain coals generate oil, calibrated 3D fluid-flow and compositional basin simulation, and new deepwater exploration models. Some remaining enigmas include poorly constrained input for deterministic volumetric models, insufficient treatment of statistical ranges of input values to basin models to assess output sensitivity, limited ability to predict the regional quality of accumulated hydrocarbons, and inadequate advances in reservoir geochemistry.

What is the future of petroleum geochemistry? As exploration and production become more difficult in the twenty-first century, petroleum geochemistry will continue to gain importance as a tool to reduce risk. The challenge is to make it an even more reliable predictive science. 


\section{Perspectives on the geological time scale for the 21st century}

Felix Gradstein - Maneveien 38, 1337 Sandvika, Norway. E-mail: felix.gradstein@geologi.uio.no

Ogg, James, Earth \& Atmos. Sci. Purdue Univ., W. Lafayette, IN 47907-1397, USA.

In this discussion, different viewpoints are offered on three aspects of the evolving geological time scale:

1. Chrono-Stratigraphic Units. 'Golden spikes' (GSSP's) provide precise geochronologic definitions for stages and periods. Do GSSP's make 'time-rock units' necessary? Can some stages be replaced by absolute-time units? Maybe a new and simplified stratigraphic code will

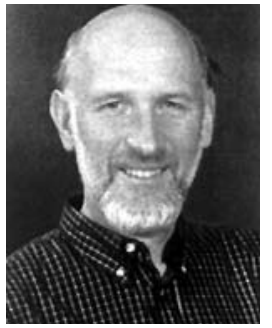
emerge in the third Millennium.

2. New Geological Stages. Some stratigraphic subcommissions, such as the Ordovician, have taken the bold initiative to strip periods off their historical regional-based stages and develop new broad stages fixed to global correlations and associated boundary stratotypes. In contrast, a trend in the Cenozoic is to advocate very short new stages between a golden spike and the classical boundaries of a historical regional stage.

3. The Time Scale Game. It is rare that a stage boundary contains horizons suitable for radiometric age dating, therefore estimates of stage boundaries are obtained by diverse interpolation methods. This includes use of astronomical cycles, correlation to marine magnetic anomaly profiles, maximum-likelihood statistics, spline fits, and biostratigraphic zonal counts. A further challenge is to incorporate uncertainties from the diverse suite of constraints. Our philosophy is that a better understanding of evolving methodologies in establishing the time scale will enhance consensus and benefit applications in earth sciences.

\section{Micromineralogy - mineralogy of the XXI Century}

\author{
R.I. Koneev - Tashkent State University, Tashkent, Uzbekistan. \\ E-mail: IKoneev@central.nbu.com
}

\begin{abstract}
Micromineralogy - a new scientific direction of modern mineralogy appeared with the discovery of the "size-property" dependence in natural mineral-geochemistry systems. This dependence is well studied in small particles physics (thin metal films, powders, etc.). Small particles are observed as special aggregate status of a matter with abnormal properties. Abnormality is connected with "size effects"-the changing of physical,
\end{abstract}

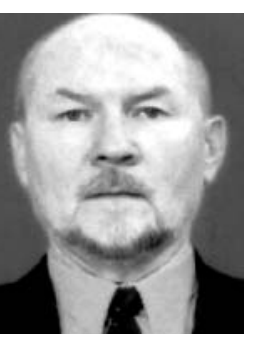
thermodynamic and other properties of a matter as a result of the sharp increasing of the role of specific surface energy with sizes of individuals $50-150 \mathrm{mkm}$ according to habitus and crystal structure. The main objects of micro-mineralogy are: micromineral—a kind of mineral type whose properties are defined by small $(100 \mathrm{mkm})$ sizes of selection; micro-paragenesis-an association of microminerals which appears during the process limited in space and time and defined by physics and chemistry laws and size effects. Micromineralogy has the special value in researches on thindisperse ores whose industry costs are dependent on elements with concentration $0.0000 \mathrm{n}-0.000 \mathrm{n} \%$ (Au, Te, Se, etc.). In such ores the capillary mineral-geochemical systems are developed, forming unusual, sometimes forbidden, micro-paragenesis of micro-minerals which do not exist in massive phases. The development of micromineralogy is connected to the application of high-precision methods (electro-sound microanalysis and others). In the XXI century such methods might be as usual as optical microscope today.

\section{Hutchison 'Young Scientist' Fund}

William Watt Hutchison, "Hutch" to his many friends around the world, was a Scots-born Canadian geologist who served Canada and the IUGS in myriad dynamic and creative ways. Most notably, he served as the IUGS Secretary General (1976-1980) at a pivotal time in its history, and as IUGS President (1984-1987). The same boundless energy, enthusiasm, skill in communications, and ability to foster teamwork that characterized his work with the IUGS also carried him to preeminent scientific administrative positions in the Canadian Government, where he served as Director General of the Geological Survey of Canada and as Assistant Deputy Minister of Earth Sciences. His distinguished career was terminated in 1987 by his untimely death at the age of 52, following a painful struggle with cancer.

One of Hutch's last wishes was to establish under IUGS auspices a memorial foundation intended to promote the professional growth of deserving, meritorious young scientists from around the world by supporting their participation in important IUGS-sponsored conferences.

The Hutchison "Young Scientist Foundation" is a worthy cause that honors a fine, caring man and a distinguished, public-spirited scientist and administrator. The foundation also celebrates and promotes those things that gave Hutch the most professional satisfaction: geology, international scientific collaboration, and stimulating young minds.

The IUGS welcomes contributions to the Hutchison "Young Scientist Foundation." Please send donations to:

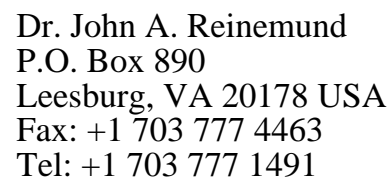

Checks in US dollars or Visa/Mastercard (please include account number and expiration date) are preferred in order to avoid the high cost of currency conversions. Residents of the U.S.A. are reminded that charitable gifts of this nature are tax deductible. 